\title{
Survey of locked facilities in Scottish psychiatric hospitals
}

\author{
Alan Smith
}

\begin{abstract}
A postal questionnaire survey of intenstve care units/ locked wards in Scottish poychiatric hospltats revealed a lack of structural securtly features (other than a locked door) and an absence of personal alarm systems for staff in a substantial minortly of units. The main reasons for transter to locked units were physical violence to others and absconding risk, and the commonest diagnoels was schizophrenia. Transfer of in-patients not detained under mental health legistation was nol uncommon. Differences in proctice with regard to the transter process were evident. In Scotland local locked facilities play an important role in secure provision and further evaluative resecarch is required.
\end{abstract}

The open-door approach (Bell, 1955) was widely adopted by psychiatric hospitals in England and the beneficial effects were reported by a number of authors (Stern, 1957; Mandelbrote, 1958). In 1961 a Ministry of Health Working Party warned of the dangers of dispensing with all secure facilities in ordinary psychiatric hospitals in England and Wales. The widespread unlocking of wards in mental hospitals led to underprovision of local secure facilities (Bowden, 1975) and the realisation of the continuing need for such resources. Locked wards and units (other than regional secure units) in England and Wales have arisen sporadically since, and mainly as a result of local initiatives (DOH, 1992).

There has been a tendency in Scotland to retain local locked facilities, and secure care of mentally disturbed patients requiring less than the maximum security of the State Hospital at Carstairs is undertaken by psychiatric intensive care units (PICU) and locked wards in local mental illness hospitals (Basson \& Woodside, 1981). These units/wards are in line with the recommendations made by the nursing trade union, COHSE, that large psychiatric hospitals should provide locked 'special care' units to meet the short-term needs of those in-patients who are acutely disturbed and cannot be adequately managed on open wards (COHSE, 1977).

It is unclear how many secure beds serving this function exist in Scotland and there is a dearth of published research relating to current practice.

\section{The study}

Using The Hospital and Health Services Year Book (Institute of Health Services Management, 1994) which contains the names of psychiatric hospitals for each of 15 Scottish health boards and checking by telephone with individual hospitals, 15 locked units/wards were identified. Some of the smaller health boards (6) have no locked facilities, whereas the larger ones covering metropolitan areas have more than one. A questionnaire, sent to the consultant responsible for each unit/ward, asked for details concerning the unit, staff, current practice, and about the characteristics of disturbed in-patients transferred from other wards.

\section{Findings}

Fourteen completed questionnaires were returned giving a response rate of $93 \%$.

The locked units

The average number of beds in each unit was 15 (range 8-25). All the units were situated within the main hospital building or campus and 12 $(86 \%)$ were simply old wards which had been converted, the original building structure being at least 50-years-old. Eleven (78\%) units were always kept locked. Most units had at least one structural security measure such as reinforced glass, special card operated locks, double door airlocks, however, four (28\%) did not possess any particular security features other than being locked. Seven (50\%) units had no form of personal alarm system for staff. In four (28\%) units, sexes were segregated with separate male and female ward areas. Patients had separate rooms in only four (28\%) units. Eight (53\%) units had areas set aside (some with small gymnasiums) permitting supervised physical activity.

\section{The staff}

The nursing staff to patient ratio was $1: 2$ in ten units, $1: 3$ in three units and $1: 1$ in one unit. All units had at least one consultant who was responsible for the ward as a whole. Twelve 
$(86 \%)$ facilities had full-time junior medical staff. Fourteen and nine units had their own or received regular sessions from occupational therapists and social workers respectively. Only four units had any form of contact with a psychologist.

\section{Current practice and the in-patients}

Nine (64\%) units had a written policy stating the required general criteria for it to be appropriate to accept an in-patient on transfer from another ward. Only one unit stipulated that transferred patients must be formally detained under some form of mental health legislation. In 11 (79\%) units, consultants estimated that up to $15 \%$ of in-patients transferred to the units over the preceding year were informal. One unit reported that during the preceding year $46 \%$ of in-patients transferred to it were not detained under mental health legislation. Twelve (86\%) units accepted inpatients transferred from wards of other hospitals as well as from the wards of their parent hospitals.

In seven $(50 \%)$ units the practice was for inpatients referred for transfer from other wards within the parent hospital to be assessed in person by a member of the unit nursing team prior to a proposed transfer. In $13(71 \%)$ units, consultants estimated that up to $5 \%$ of referrals were rejected in the preceding year. In six (43\%) units there was a general policy not to accept for transfer certain types of in-patients, including inpatients under 16-years-old, the elderly demented, and those with personality disorder as the sole diagnosis. In $11(78 \%)$ units, consultants estimated that approximately $25 \%$ of transferred in-patients stayed up to 7 days in the unit before returning to their original ward.

Consultants estimated that the average percentage of transfers involving female in-patients was 25\% (range 5-35\%). The most frequent reasons for referral to a given unit were physical violence to others (five), absconding risk (four), generally disruptive behaviour (three), and selfharm (two). In $13(93 \%)$ units it was said that the most frequent diagnosis for transferred patients was schizophrenia while the remaining consultant stated that psychotic depression was the commonest diagnosis. In $12(86 \%)$ units 'alcohol/ drug related psychoses' and 'hypomania/mania' were the next most frequent diagnoses.

\section{Comment}

Some in-patients who present severe management difficulties in open wards of psychiatric hospitals highlight the role of local locked wards in the provision of secure psychiatric care and in turn this has considerable implications for the organisation of services. Purchasers need to formulate strategic plans to meet the needs of in-patients exhibiting short-term behavioural disturbance and hospitals are now required to assess the risks to the health and safety of staff and patients (Health and Safety Executive, 1992).

The majority of locked units in Scotland are not purpose built and it is surprising that a substantial minority have no particular security features other than a locked door. Of more concern is the lack of a personal alarm system for staff in half of the units. Plans for modernisation are ongoing and several consultants reported that replacement units are scheduled for construction.

Locked wards should not be a substitute for low staff numbers and the high nursing staff to patient ratio reported by consultants is to some extent reassuring. However, it is unclear if these figures include unqualified nursing staff. As in psychiatric in-patient services in Scotland as a whole, the apparent lack of psychology input is disappointing, particularly in a setting where behavioural techniques can play an important part in dealing with the disturbed conduct.

Differences in practice with regard to the transfer process to the locked units are evident. Many units have no written guidelines. It is practice in only half the units for designated members of their staff to examine the in-patient on the open ward and to assess suitability for transfer. Assessment of an in-patient on the open ward permits a more accurate evaluation of the need for transfer and in the event that transfer is not thought appropriate, staff from the unit can provide ongoing support and suggest alternative lines of management (Dix, 1995).

It is not surprising that physical violence to others and absconding risk were the commonest reasons reported by most consultants for transfer to the locked units. Although two consultants said that risk of self-harm was the commonest reason for transfer to their units, many of the others reported that they avoided accepting inpatients presenting this type of risk, and did not regard use of their units as a substitute for intensive nursing observation or 'specialing' of such patients on open wards. That schizophrenia was said to be the commonest diagnosis in nearly all units reflects in part the high overall numbers of such in-patients in hospitals. Many consultants expressed traditional antipathy towards accepting patients with personality disorder as the sole diagnosis.

The percentages of in-patients not detained under mental health legislation undergoing transfer to locked facilities is an area requiring further scrutiny. Informal transfer to a locked ward may be based on good pragmatic grounds but close monitoring is required. The patient should be able to give valid consent and this should be obtained prior to transfer and recorded in the case notes. 
In Scotland local locked facilities play an important role in the spectrum of secure provision. Unlike England and Wales, there are no 'regional secure units' and there is one special facility, the State Hospital at Carstairs, which provides treatment under conditions of maximum security. Increased security precautions in an ordinary psychiatric hospital can be used in an effective, therapeutic way to manage the short-term disturbed behaviours arising from the acute phase of mental illness. Further descriptive and evaluative research about current services and the effects of lack of such services in some localities is required.

\section{References}

BAsson, J. V. \& WoOdside, M. L. (1981) Assessment of a secure/intensive care/forensic ward. Acta Psychiatrica Scandinavica, 64, 132-141.

Beu, G. M. (1955) A mental hospital with open doors. International Journal of Social Psychiatry, 1, 42-48.

BOWDEN, P. (1975) Liberty and psychiatry. British Medical Journal, 4, 94-96.
CONFEDERATION OF HEALTH SERVICE Employees (1977) The Management of Violent and Potentially Violent Patients. Banstead: COHSE.

DEPARTMENT OF HEALTH (1992) Review of Health and Soctal Services for Mentally Disordered Offenders and Others Requiring Similar Services (Reed Report). Cmnd. 2088. London: HMSO.

Dxx, R. (1995) A nurse-led psychiatric intenstve care unit. Psychiatric Bulletin, 19. 285-287.

HEALTH AND SAFETY EXECUTIVE (1992) New Health and Safety at Work Regulations. Sheffleld: Health and Safety Executtive.

InstTIUTE of Health Services Management (1994) The Hospital and Health Service Year Book. London: IHSM.

MANDELBROTE, B. (1958) An experiment in the rapid conversion of a closed mental hospital into an opendoor hospital. Mental Hygiene, 42, 3-16.

MINISTRY OF HEALTH (1961) Special Hospitals: Report of a Working Party (The Emery Report). London: HMSO.

STERN, E. S. (1957) Operation sesame. Lancet. 1, 577-578.

Alan D. Smith, Clinical Lecturer in Forensic Psychiatry, Institute of Criminology, University of Cambridge, 7 West Road, Cambridge CB3 9DT

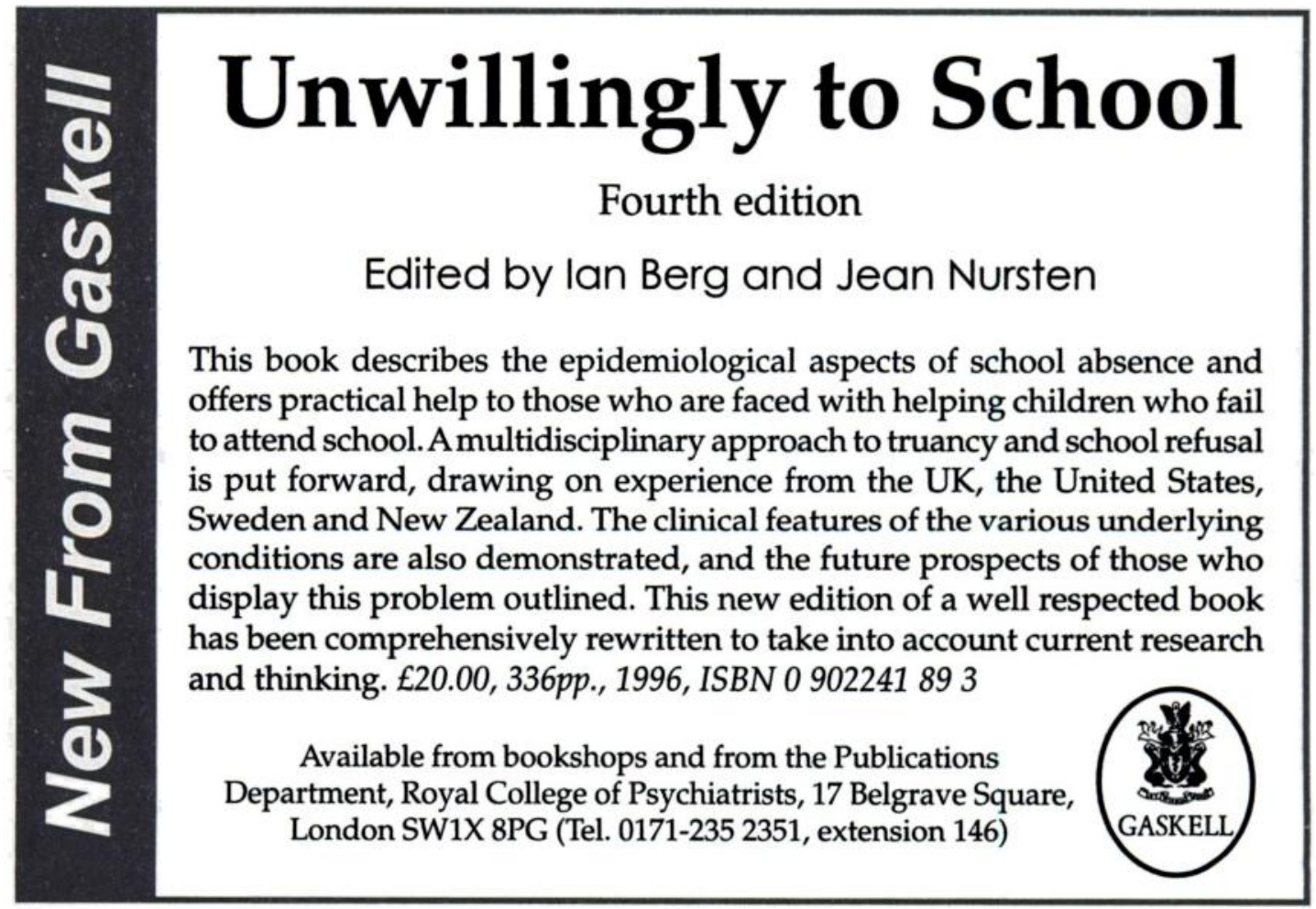

